\title{
Effect of Weight Bearing Exercises on Osteoporosis in Breast Cancer Patients Receiving Chemotherapy
}

\author{
ZAKARIA M.E. MOWAFY, Ph.D.*; KHOWAILED A. KHOWAILED, M.D.** and \\ EMAN M. EL-GENDY, M.Sc.* \\ The Department of Physical Therapy for Surgery, Faculty of Physical Therapy, Cairo University* and \\ The Department of Surgery, Faculty of Medicine, Beni Suef University**, Egypt
}

\begin{abstract}
Background: Bone is a piezoelectric material and consequently, it exhibits the converse piezoelectric effect (mechanical deformation under the influence of an applied electric field).

Aim of Study: To evaluate the efficacy of the treadmill weight bearing exercises on Bone Mineral Density (BMD) and T-score mean in cases of osteoporosis in breast cancer patients receiving chemotherapy.

Material and Methods: Thirty breast cancer patients receiving chemotherapy and complaining from osteoporosis were randomly divided into two groups. Group (A) received aerobic exercise on treadmill as form of weight bearing exercise 20 minutes 3 times per week for 2 months and drug therapy (vitamin D supplements and calcium). Group (B) received only drug therapy (vitamin $\mathrm{D}$ supplements and calcium).

Results: The results showed that the treadmill weight bearing exercises and drug therapy application) had a valuable effects more than application of the drug therapy alone in improving on the Bone Mineral Density (BMD) in cases of osteoporosis in breast cancer patients receiving chemotherapy.

Conclusion: Application of the treadmill weight bearing exercises and drug therapy had fruitful effects more than application of the drug therapy alone in cases of osteoporosis in breast cancer patients receiving chemotherapy as evidenced by the highly significant decrease in BMD and T-score mean.
\end{abstract}

Key Words: Treadmill weight bearing exercises - Bone mineral density - T-score - Osteoporosis.

\section{Introduction}

CANCER rehabilitation has been defined as "the dynamic process directed toward the goal of enabling persons to function at their maximum level of their disease or disability in terms of their physical, mental, emotional, social, and economic potential. Four major problems presented to the

Correspondence to: Dr. Zakaria M.E. Mowafy, The Department of Physical Therapy for Surgery, Faculty of Physical Therapy, Cairo University, Egypt rehabilitation team by patients with breast cancer populates include: Lymphedema, decreased shoulder mobility, pain and fatigue, and need for psychosocial support to foster good functional outcome and independence [1-3].

Chemotherapy can damage bone marrow and therefore impair the production of white blood cells, platelets and red blood cells. The resulting anemia decreases the oxygen transport capacity of blood and hence the oxygen supply to the cells. Cardio toxic cytostatic agents like anthracyclines and bleomyzcim can cause reduction in cardiac output and hence impairment in the blood supply to the muscles [1-5].

Osteoporosis is a systemic, skeletal disease characterized by low bone density and microarchitectural deterioration of bone tissue, with a consequent increase in bone fragility. It is a serious disease that is increasing at an epidemic rate and it is predicted that osteoporosis and osteoporotic fractures will rise exponentially over the next 50 years, as the population ages. Osteoporosis is still a serious health problem exercise, worldwide influencing the quality of life and imposing social and financial problems associated with transplantation is the treatment of choice for end-stage with considerable morbidity. Osteoporosis is characterized by low Bone Mineral Density (BMD) resulting into an increased risk of fracture. Fractures caused mostly by osteoporosis can be induced by both (e.g., genes and hormones) and external (e.g., life style) factors [6-10]

Some diseases can influence bone metabolism and as a result on BMD and Bone Mineral Content (BMC). End-stage renal disease patients can be liable to osteoporosis due to low dietary calcium 
intake, reduced exercise, heparin therapy, low body weight, amenorrhea, premature menopause and renal osteodystrophy. Exercise may have positive effects on bone density in young adult women preventing osteoporosis. A positive correlation is noticed between exercise and BMD in healthy people and also among end stage renal disease patients are at risk of osteoporosis due to low dietary calcium intake, reduced exercise and heparin therapy [11-14]

The primary cause of Osteoporosis is hormonal imbalances that interfere with the bone-forming cells. The osteoblasts are specialized bone cells that function to pull calcium, magnesium and phosphorus from the blood in order to build bone mass. Osteoblasts require the hormone progesterone to maintain youthful, bone-forming capability during and after menopause. Young women with amenorrhea (absence of menstrual cycle), short luteal phases or other ovulation disturbances show an increased bone density when given synthetic progesterone (medroxyprogesterone). Estrogen therapy has significant risks that include an increaseriskofuterineandbreastcancer [6,15-18] .

Weight-bearing activity, can be thought of as any activity that is done while upright, requiring the bones to fully support the body's weight against gravity. Impact-loading and weight-bearing activity, therefore, involves some impact or force being transmitted to the skeleton during weight bearing. Examples of impact-loading, weight-bearing exercises include walking, jogging, stair climbing, dancing, weight training and cross-country skiing. Activities that involve less impact and less weightbearing force include swimming and bicycling. While weight bearing and impact loading stimulate the development of healthy bones, it must be remembered that for exercise to be effective, the mechanical stress placed on the bone by an activity, must exceed the level to which the bone has adapted (i.e., short periods of intense loading can produce more new bone than long-term routine loading) $[15,16,19,20]$

Weight bearing aerobic exercises and musclestrengthening exercises has been shown to be an integral part of osteoporosis prevention, as well as a part of the treatment process. Lifetime weightbearing is more strongly associated with higher $\mathrm{BMD}$ of the total and peripheral skeleton than is non-weight-bearing exercise. Physical activity, particularly weight-bearing exercise, is thought to provide the mechanical stimuli or "loading" important for the maintenance and improvement of bone health. There is consistent evidence that weight- bearing exercise during youth contributes to increased peak bone mass and provides the mechanical stimuli or 'loading' important for the maintenance of bone health and to minimize the rate of bone loss later in life [19-22]

In general, physicians and physical therapists take the following steps to determine Osteoporosis: Bone Mineral Density (BMD) is measured, typically in the hipbone, spine and forearm. Using low-dose X-rays with an approach referred to as bone densitometry, measurements of BMD are given as $\mathrm{mg} / \mathrm{cm}^{2}$, which is the average concentration of bone mineral in the areas that are scanned with the imaging tests. However, physicians often take additional factors into the calculation when predicting more precisely the risk for fracture. To determine Standard Deviation (SD) from this norm, $\mathrm{SD}$ results are given as $\mathrm{Z}$ and $\mathrm{T}$ scores $[11,14,20,22]$

\section{Material and Methods}

\section{Subjects:}

This study was carried out on thirty breast cancer patients receiving chemotherapy and complaining from osteoporosis were participated in this study; their ages were ranged from 35 to 55 years, they were selected from the National Cancer Institute in 2017. These patients were divided into two equal groups in number: Group A (weight bearing exercises group): Fifteen breast cancer patients receiving chemotherapy and complaining from osteoporosis received aerobic exercise on treadmill as form of weight bearing exercise 20 minutes 3 times per week for 2 months and drug therapy (vitamin D supplements and calcium). Group B (control group): Fifteen breast cancer patients receiving chemotherapy and complaining from osteoporosis received only drug therapy (vitamin D supplements and calcium). Measurements were conducted before starting the treatment as a first record and at the second month of treatment as final record.

\section{Instrumentation:}

In this study the measuring tools were the absorptiometry (DXA) is a clinically proven method of measuring Bone Mineral Density (BMD) in the lumbar spine, proximal femur, forearm, and whole body. It is used primarily in the diagnosis and management of osteoporosis and other disease states characterized by abnormal BMD, as well as to monitor response to therapy for these conditions, while the therapeutic equipment was the electronic treadmill Kettler-marathon model No 7899-800, made in Germany (as form of weight bearing exercises), which was adjusted to the subject's 
comfortable walking speed. Generally, during the treadmill training, its speed and inclination are electronically adjusted, and it is also provided with a control panel to display the exercise parameters. It allow for the comfortable running without joint or back pains through a perfect combination between aluminium-pertinax running deck, shock absorbers and overall shock-damping design in addition to the and drug therapy (vitamin D supplements and calcium [6,9,12,14,22] .

\section{Procedures:}

\section{Evaluation:}

Technical assessment procedure was conducted through: DEXA (dual-energy X-ray absorptiometry): Measuring the patient bone density by using DEXA before starting the program and by the end of the problem, the DEXA (dual energy X-ray absorptiometry), is the most common and widely used test for osteoporosis. This test measures the amount of calcium in bone, typically at the hip and lower spine. The DEXA scan should be repeated every couple of years to check whether bone density has changed. T-score compares results to healthy bones of young adults. The following table shows the range of T-scores that are used to assess risk. The examination was performed by a technologist with the following qualifications and responsibilities: Responsibility for patient comfort and safety, preparing and properly positioning the patient, placement of regions of interest for BMD measurements, monitoring the patient during the measurements, and obtaining the measurements prescribed by the supervising physician. Documented formal training in the use of the DXA equipment, including all manufacturer-specified Quality Assurance (QA) procedures. Knowledge of and familiarity with the manufacturer's operator manual for the specific scanner model being used. Standard DXA examination was consisted of a Posteroanterior (PA) scan of the both hips. Positioning and soft-tissue-equivalent devices issued by the manufacturer were used consistently and properly. Comfort devices, such as pillows under the head or knees, were not interfere with proper positioning and were never appear in the scan field. T-scores was calculated by taking the difference between a patient's measured BMD and the mean BMD in healthy young adults, matched for gender and ethnic groups, and expressing the difference relative to the young adult population standard deviation: Where normal $\mathrm{T}$-score $=\mathrm{T}>-1.0$, Osteopenia $=-2.5<$ $\mathrm{T}<-1.0$, Osteoporosis $=-2.5<\mathrm{T}<-1.0$ and the established osteoporosis $=\mathrm{T}<2.5$ in the presence of 1 or more fragility fractures accoording to the following equation $[\mathbf{5 , 1 1 , 1 4 , 1 8 , 2 0 - 2 2 ]}$ BMD.

T-score $=$ Measured BMD-Young adult mean

Young adult population standard deviation.

\section{Treatment procedures:}

The procedures of treatment application were achieved by electronic treadmill (form of weight bearing exercise) under the following steps: Exercises were applied three times weekly for a total period of treatment for 2 months and 20 minutes for every session. These exercises were divided into 3 components as follow: A-Warm up phase: Simple stretching exercises for all muscle groups then walking for 5 minutes on the treadmill at lowest speed. B-Active phase: When patient attended for treatment was received full explanation to the purpose of the treatment, the therapeutic and physiological benefits of this method of treatment. Before starting the treatment, all the previous measurements of each patient were taken for a comparison. Duration: 10 minutes. Intensity: Training program preceded from 50 to $55 \%$ in the first 2 weeks, 55 to $60 \%$ in the second 2 weeks, 60 to $65 \%$ in the third 2 weeks and 65 to $70 \%$ of maximum heart rate in the last 2 weeks according to the (Karvonen formula); MHR=220-age. Cool down Phase: Simple stretching exercises for all muscle groups then walking for 5 minutes on the treadmill at lowest speed $[13,15,16,18,19,21]$.

\section{Data analysis:}

Bone Mineral Density (BMD) in $\mathrm{gm} / \mathrm{cm}^{2}$ and the T-score mean of the hip bone in $\mathrm{gm} / \mathrm{cm}^{2} \%$, were measured pre-treatment as a first record and after two months as a second final record in both groups. Collected data were fed into computer for the statistical analysis; descriptive statistics as mean, standard deviation, minimum and maximum were calculated for each group. The $t$-test was done to compare the mean difference of the two groups before and after application and within each group. Alpha point of 0.05 was used as a level of significance $[23,24]$.

\section{Results}

As shown in (Table 1) and Fig. (1), the mean value of the BMD before treatment was $(0.7156 \pm$ $0.0560) \mathrm{gm} / \mathrm{cm}^{2}$ in the study group, while after treatment was $(0.4805 \pm 0.1026) \mathrm{gm} / \mathrm{cm}^{2}$. These results revealed a highly significant increase in $\mathrm{gm} / \mathrm{cm}^{2}(p<0.0001)$. While in the control group, the mean value of the BMD before treatment was $(0.7906 \pm 0.1016) \mathrm{gm} / \mathrm{cm}^{2}$, while after treatment was $(0.7904 \pm 0.1021) \mathrm{gm} / \mathrm{cm}^{2}$. These results re- 
vealed non-significant difference in the BMD ( $p$ $>0.05$ ).

As shown in (Table 2) and Fig. (2), the mean value of the T-score mean of the hip bone in $\mathrm{gm} /$ $\mathrm{cm}^{2} \%$ before treatment was $(-1.0226 \pm 0.75781)$ $\mathrm{gm} / \mathrm{cm} \%$ in the study group, while after treatment was $(-2.0220 \pm 0.1662) \mathrm{gm} / \mathrm{cm}^{2} \%$. These results revealed a highly significant increase in the Tscore mean of the hip bone $(p<0.0001)$, while in the control group, the mean value of the T-score mean of the hip bone in $\mathrm{gm} / \mathrm{cm}^{2} \%$ before treatment was $(-2.01865 \pm 0.1653) \mathrm{gm} / \mathrm{cm}^{2} \%$, while after treatment was $(-2.0288 \pm 0.1643) \mathrm{gm} / \mathrm{cm}^{2} \%$, these results revealed non-significant difference in the $\mathrm{T}$-score mean of the hip bone $(p>0.05)$.

Table (1): Comparison of the mean values of the Bone Mineral Density (BMD) in $\mathrm{gm} / \mathrm{cm}^{2}$ before and after treatment in the study and control groups.

\begin{tabular}{|c|c|c|c|c|c|c|c|c|}
\hline & \multicolumn{2}{|c|}{ Before treatment } & \multicolumn{2}{|c|}{ After treatment } & \multirow{2}{*}{$\begin{array}{c}\text { Mean } \\
\text { difference }\end{array}$} & \multirow{2}{*}{$\begin{array}{c}t- \\
\text { value }\end{array}$} & \multirow{2}{*}{$\begin{array}{c}p- \\
\text { value }\end{array}$} & \multirow{2}{*}{$\begin{array}{l}\text { Level of } \\
\text { significance }\end{array}$} \\
\hline & Mean & $\mathrm{SD} \pm$ & Mean & $\mathrm{SD} \pm$ & & & & \\
\hline Study group & 0.7156 & 0.0560 & 0.4805 & 0.1026 & 0.235100 & 7.79 & 0.0001 & $\mathrm{~S} \uparrow$ \\
\hline Control group & 0.7906 & 0.1016 & 0.7904 & 0.1021 & 0.000200 & 0.01 & 0.996 & N.S. \\
\hline
\end{tabular}

Table (2): Comparison of the mean values of the T-score mean of the hip bone in $\mathrm{gm} / \mathrm{cm}^{2} \%$ before and after treatment in the study and control groups.

\begin{tabular}{|c|c|c|c|c|c|c|c|c|}
\hline & \multicolumn{2}{|c|}{ Before treatment } & \multicolumn{2}{|c|}{ After treatment } & \multirow{2}{*}{$\begin{array}{c}\text { Mean } \\
\text { difference }\end{array}$} & \multirow{2}{*}{$\begin{array}{c}t- \\
\text { value }\end{array}$} & \multirow{2}{*}{$\begin{array}{c}p- \\
\text { value }\end{array}$} & \multirow{2}{*}{$\begin{array}{l}\text { Level of } \\
\text { significance }\end{array}$} \\
\hline & Mean & $\mathrm{SD} \pm$ & Mean & $\mathrm{SD} \pm$ & & & & \\
\hline Study group & -1.0226 & 0.7579 & -2.0220 & 0.1662 & 0.999400 & 4.99 & 0.0001 & $\mathrm{~S} \downarrow$ \\
\hline Control group & -2.01865 & 0.1653 & -2.0288 & 0.1643 & 0.010150 & 0.17 & 0.867 & N.S. \\
\hline
\end{tabular}

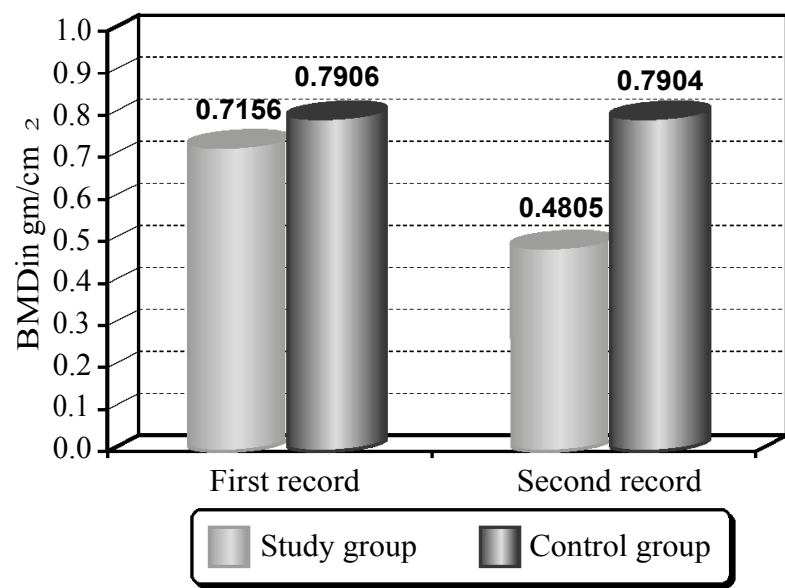

Fig. (1): Mean values of the BMD before and after treatment in both groups.

\section{Discussion}

Osteoporosis is a silent disease (a symptomatic occurs slowly over time) defined as a systemic skeletal disease characterized by low bone mass and micro architectural deterioration of bone tissues leading to enhanced bone fracture and consequent increase in fracture risk especially of the hip (proximal femur associated with the highest morbidity and mortality, particularly amongst elderly women and men), spine (vertebral crush or wedge fractures, which may lead to loss of height, kyphosis and

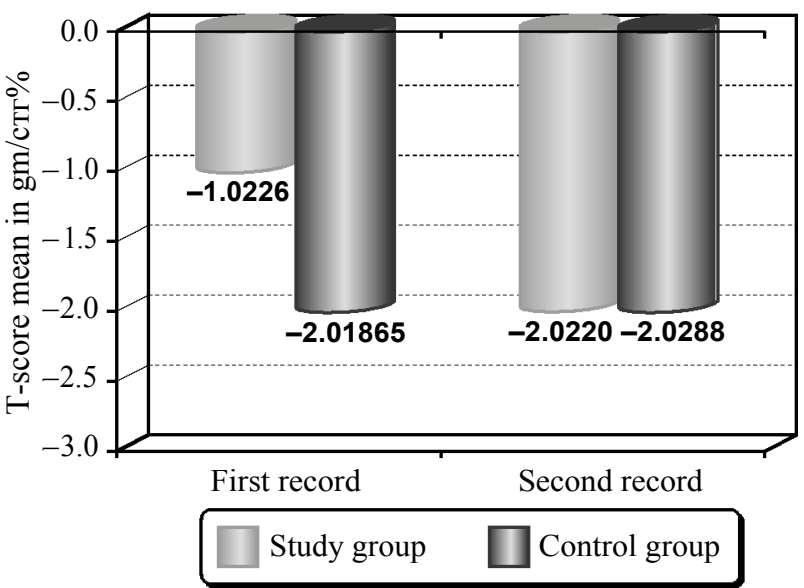

Fig. (2): Mean values of the T-score mean of the hip bone in $\mathrm{gm} / \mathrm{cm} \%$ of the 2 records in both groups.

chronic back pain) and wrist (Colles' fracture-distal radius) [6-8]

Osteoporosis is diagnosed when bone density has decreased to the point where fractures will happen with mild stress, the so-called fracture threshold. Measuring bone density and comparing the results with the normal will determine this. It should be noted that low scores on bone density are not very accurate in determining fracture risk without consideration of other risk factors for fracture. Silent disease is the name of Osteoporosis 
because bone loss occurs without symptoms; people may not know that they have Osteoporosis until their bones become so weak that a sudden strain, bump or fall causes a fracture or a vertebra to collapse. Collapsed vertebrae may initially be felt or seen in the form of severe back pain, loss of height or spinal deformities such as kyphosis or stooped posture. Individuals who have not had any fractures but do have a number of risk factors for Osteoporosis need an examination called a bone density test to determine if Osteoporosis is present $[4,5,9,10]$.

Bone loss has been found in post-menopausal women and older men with prolonged smoking exposure. Deficits ranging from 0.5 to 1.0 standard deviation have been identified in these groups. In addition, a relationship between cigarette smoking and low bone density in adolescence and early adulthood has been identified. Smokers are often thinner than their non-smoking counterparts, smokers also tend to have a higher consumption of alcohol, may be less physically active, often have nutritional deficiencies and tend to have an earlier menopause than non-smokers. These characteristics place many smokers at an increased risk of Osteoporosis, apart from their tobacco consumption $[8,9,11,20]$

The primary cause of osteoporosis is hormonal imbalances that interfere with the bone-forming cells. The osteoblasts are specialized bone cells that function to pull calcium, magnesium and phosphorus from the blood in order to build bone mass. Osteoblasts require the hormone progesterone to maintain youthful, bone-forming capability during and after menopause. Young women with amenorrhea (absence of menstrual cycle), short luteal phases or other ovulation disturbances show an increased bone density when given synthetic progesterone (medroxyprogesterone). Estrogen therapy has significant risks that include an increased risk of uterine and breast cancer $[\mathbf{4 , 7 , 8 , 2 5}]$

There are three different exercise programmes to consider in connection with Osteoporosis: 1 Preventive Exercise Programme, 2- Exercise Programme for Osteopenia and 3- Exercise Programme for Advanced Stage Osteoporosis. A moderate exercise programme, emphasizing weight-bearing activities and resistive or strength training, is recommended. A weight-bearing exercise simply means bones and muscles are working against gravity. This is any activity in which the feet and legs are bearing the body weight including: Walking, jogging, hiking, dancing, low-impact aerobics, stair climbing and racquet sports. Swimming and biking, although great aerobic exercise, are not weight-bearing exercises. Gentle seated aerobic exercise is better than weight-bearing exercises. (i.e. chair aerobics or non-resistive cycling). Water aerobics/exercises and swimming are ideal since the water reduces risk of falling, promotes flexibility and provides non-impact resistance exercise. In the most advanced stages, only bed exercises should be attempted. As above, postural education and exercises should be prescribed. A good fall prevention programme and gentle exercises to strengthen the upper and lower back are desirable. While bone mineral loss is apparent in post-menopausal women, research has shown that low to moderate intensity exercise can help increase bone mineral density in pre-menopausal women. It was found that women who participated in a low to moderate intensity exercise regimen had higher bone mineral densities than women who were not exercising regularly $[\mathbf{6 - 8 , 1 0 , 1 1 , 2 5 ]}$

The findings of the present study showed nonsignificant differences in the pre-treatment records of both BMD and T-score mean of the hip bone between the mean values of the study and the control groups.

Results of the study group revealed a highly significant increase in the mean values of both BMD and T-score mean of the hip bone, after application of the treadmill weight bearing exercises, when compared against the pre-application results.

Significant differences, between the study group (Treadmill weight bearing exercises and drug therapy application) and the control group (only drug therapy application), which were in the form of a highly significant increase in the BMD and T-score mean were consistent with those observed and recorded by Baddoura, 2010; Ballard et al., 2011; Bonnick, 2009; Candus, 2009; Kennedy et al., 2009; Kohrt et al., 2010; Lazarus et al., 2010; Micklesfield et al., 2006; Prince et al., 2005; Simkin and Ayalon, 2006; Susan, 2002; Teegarden et al., 2005 and Winters et al., 2006.

Results of this study support the expectation that application of the treadmill weight bearing exercises and drug therapy had fruitful effects more than application of the drug therapy alone in cases of osteoporosis in breast cancer patients receiving chemotherapy as evidenced by the highly significant decrease in BMD and T-score mean.

\section{Conclusion:}

Application of the treadmill weight bearing exercises and drug therapy had fruitful effects more 
than application of the drug therapy alone in cases of osteoporosis in breast cancer patients receiving chemotherapy as evidenced by the highly significant decrease in BMD and T-score mean.

\section{References}

1- ABRAHAM J.C. and ZUJEWSKI J.A.: "Breast cancer" In: Abraham J. and Allegra C.J. "Bethesda Hand book of clinical Oncology" 1 st Ed, Chap. 11, Lippincott, Williams, Wilkins, Philadelphia, Pp. 128, 2009.

2- CARNEL S.B., BLAKESLEE D.B. and OSWALD S.G.: Treatment of radiation and chemotherapy-induced stomatitis. Otolaryngol Head Neck Surg., 112: 226-30, 2010.

3- LAZARUS H.M., HUARD D.W. and GORDON G.P.: Intensive melphalan chemotherapy and cryopreserved autologous bone marrow transplantation for the treatment of refractory cancer. Journal of Clinical Oncology, 1: 359 67, 2010.

4- KENNEDY C.A., NICHOLAS R.A. and HARDEN T.K.: Differential coupling of human $\mathrm{P} 2 \mathrm{Y} 11$ receptor to phospholipase $\mathrm{C}$ and adeylyl cyclase. Br. J. Pharmacol., 126: 22, 2009.

5- WINTERS K.M., ADAMS W.C. and MEREDITH C.N.: "Bone density and cyclic ovarian function in trained runners and active controls. Medicine and Science in Sports and Exercises, 28 (1): 776-85, 2006.

6- BADDOURA G.F.: Rev Epid Santa Publique, 2/01, 49 (1): 27-32. 8. Memon et al. Int. J. Epid., 1998; 27 (5): 860. www.kfshrc.edu.sa/medicine/files/osteoporosis\% 20guidelines.pdf, 2010.

7- BULTINK I.E. and LEMS W.F.: "Osteoarthritis and osteoporosis: What is the overlap." Curr. Rheumatol. Rep., 15: 328, 2013.

8- DAREEN F.H.: Definitions bone diseases and dental fluorosis; administration material: [O] steoporosis is defined as a condition in which the bone mass per unit volume (density) of normally mineralized bone is reduced. www.fluoridation.com/definit.htm. 2008.

9- SUSAN O.D.: "Osteoporosis and bone physiology and prevention of Osteoporosis" Dr. Otts. excellent www. Osteoporosis, 2002.

10- TERRIO K.T. and AULD G.W.: Osteoporosis knowledge, calcium intake, and weight-bearing physical activity in three age groups of women. Exercise and Sport Sciences Reviews, 11 (3): 66-75, 2006.

11- BAIM S.H., BINKLEY N.G. and BILEZIKIAN J.P "Official positions of the international society for clinical densitometry and executive summary of position development conference." J. Clin. Densitom., 11: 75-91, 2008.
12- BONNICK S.L.: Bone densitometry; bone density loss with aging. Percentage of US caucasian women in WHO categories. Age 25, Age 50, Age 65, Age 80. courses. washington.edu/bonephys/opbmd.html-9k, 2009.

13- CHRISTOPHER G.D., BRUCE E.D. and MARGERY L.S.: Gass. Position Statement Management of posts menopausal Osteoporosis: Position statement of the North American Menopause Society". J. of the North American Menopause Society." Vol. 9, No. 2, pp. 84-101, 2002.

14- GHANNAM N.N., HAMMAMI M.M. and KHAN B.A.: Bone mineral density of the spine and femur in healthy Saudi females: Relation to vitamin D status, pregnancy, and lactation. Calci. Tissue Int., 65: 23-8, 2009.

15- BALLARD J.E., McKEOWN B.C. and GRAHAM H.M.: The effect of high level physical activity (8.5 METs or greater) and estrogen replacement therapy upon bone mass in postmenopausal females aged 50-68. Int. J. Sports Med., 11 (3): 208-14, 2011.

16- CANDUS G.F.: Five exercises a person can do if they have osteoporosis. J. Auton. Nerv. Syst., 11 (2-5): 1559, 2009.

17- MICKLESFIELD L.K., FATAAR A.B. and MYBURGH K.H.: Bone mineral density in mature, pre-menopausal ultramarathon runners. Medicine and Science in Sports and Exercise, 27 (5): 688-96, 2006.

18- SIMKIN A.G. and AYALON J.A.: Bone-loading: The new way to prevent and combat the thinning bones of osteoporosis. London: Prion, 2006.

19- DRINKWATER B.L. and McCLOY B.E.: "Does physical activity play a role in preventing osteoporosis?" Research Quarterly for Exercise and Sport, 65 (3): 197-206, 2010.

20- KOHRT W.M., EHSANI A.A. and BIRGE S.J.: HRT preserves increases in bone mineral density and reductions in body fat after a supervises exercise program. Journal of Applied Physiology, 84 (5): 1506-12, 2010.

21- PRINCE R.H., DEVINE A.A. and DICK I.R.: The effects of calcium supplementation (milk powder or tablets) and exercise on bone density in postmenopausal women. J. Bone Miner. Res., 10 (7): 1068-75, 2005.

22- TEEGARDEN D.W., JOHNSTON C.R. and WEAVER C.W.: Peak bone mass in young women. Journal of Bone and Mineral Research, 10: (5), 711, 2005.

23- HINTON P.R.: "Statistics Explained" 2 nd Ed. Rutledge Taylor and Francis Group London, Pp. 149-55, 2004.

24- PIPKIN F.B.: Medical statistics made easy; Edinburgh London; Melbourne and New York, 1984.

25- DALSKY G.A., STOCKE K.S. and EHSANI A.A.: Weight bearing exercise training and lumbar bone mineral content in postmenopausal women. Ann. Intern. Med., 108: 8248, 2006. 


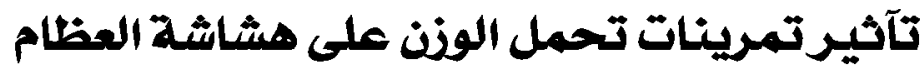

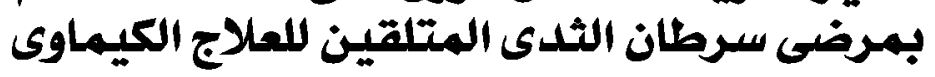

كان الهدف من البحث هو إستكثاف فاعلية كلا من تمرينات تحميل الونن والعلاج الدوائى (فيتامين دال والكالسيوم) على هشاشة العظام

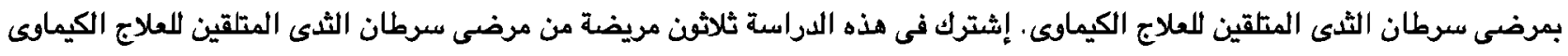

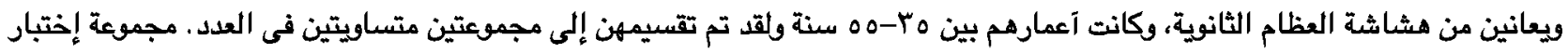

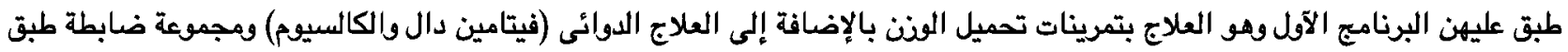

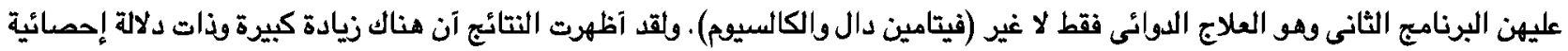

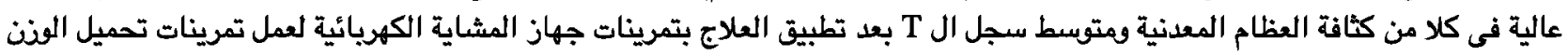

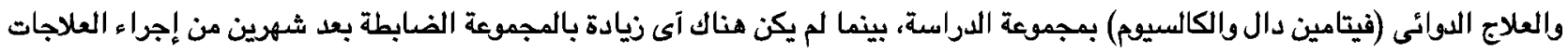

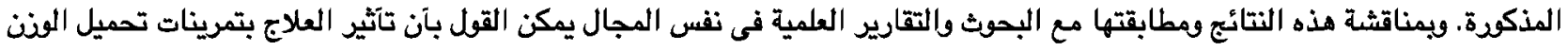

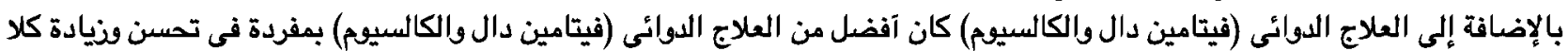

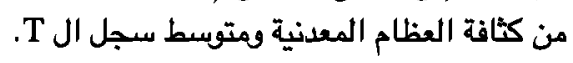

